University of Arkansas at Little Rock William H. Bowen School of Law Bowen Law Repository: Scholarship \& Archives

Faculty Scholarship

1997

\title{
Crime Control and Harassment of the Innocent
}

Raymond Dacey

ksgallant@ualr.edu

Kenneth S. Gallant

Follow this and additional works at: https://lawrepository.ualr.edu/faculty_scholarship

Part of the Criminal Law Commons, and the Law Enforcement and Corrections Commons

\section{Recommended Citation}

Raymond Dacey and Kenneth S. Gallant, Crime Control and Harassment of the Innocent, 25 Journal of Criminal Justice 265, 325 (1997).

This Article is brought to you for free and open access by Bowen Law Repository: Scholarship \& Archives. It has been accepted for inclusion in Faculty Scholarship by an authorized administrator of Bowen Law Repository: Scholarship \& Archives. For more information, please contact mmserfass@ualr.edu. 


\title{
CRIME CONTROL AND HARASSMENT OF THE INNOCENT
}

\author{
Raymond Dacey and Kenneth S. Gallant \\ College of Business and Economics and College of Law \\ University of Idaho \\ Moscow, Idaho 83844
}

\begin{abstract}
Crime control through law enforcement is generally considered to be a two-part process of appreinending and incapacitating or rehabilitating the guilt; and deterring the innocent from crime by the inreat of punishment. The analysis presented here show's that the protection of the innocent from harassment-detention, arrest. punishment, and other intrusions by the criminal justice system-is important in deterring crime. Specincally; the analysis show's that deterrence from crime is weakened and then lost ior a rational individual who holds the majorit: attitude toward risk, if the levels of rightful punishment and wrongful harassment are increased, as in a war on crime, and the likelihoods of wrongful and rightinl punishment are reasonably close. The analy sis is employed to show how the perceived likelihood of inarassment may be a contributing factor to the disproportionately high representation of minority groups in the U.S. prison șistem. (C) 1997 Elsevier Science Ltd
\end{abstract}

\section{INTRODLCTION}

This article establishes that, under certain conditions, individuals are encouraged to commit crimes by a belief that the criminal justice sy'stem may act against them whether or not they commit crimes. Thus, protection of the innocent from police harassment may itself deter crime, and harassment of the innocent by the criminal justice system may encourage crime. The latter result is used to hypothesize a partial explanation of the ethnic demographics of the U.S. prison population that is superior to the conventional argument that criminals are inveterate risk takers. This explanation is generaliz- able to cases where members of a particular social group perceive themselves to be unfairly treated by law enforcement agents.

The criminal justice system is considered to help control crime because the likelihood of being apprehended and punished deters persons from committing crimes. Additionally, by the apprehension, conviction, and punishment of persons who have committed crimes, the system incapacitates and, with any luck, rehabilitates criminals. Only deterrence, and not incapacitation or rehabilitation, is examined in this article.

One side effect of the criminal justice system is the potential for harassment, apprehension, 
and punishment of persons who have not committed crimes, or at least have not committed the crimes for which they are being investigated, apprehended, or charged. A simple rational actor model, an extension of the traditional economic model of Becker (1968, 1995), establishes the following result: For the majority of individuals, a belief that the likelihood of harassment is not reasonably lower than the likelihood of proper punishment encourages the commission of crimes.

\section{DECISION ANALYSIS AND ATMTUDE TOWARD RISK}

The analysis presented here is an extension and refinement of the rational actor model employed in the economic and game-theoretic analyses of the decision to commit a crime. The present analysis extends these analyses of crime by including a more contemporary treatment of attitude toward risk and the costs imposed on nonparticipants in crime by the criminal justice system.'

The rational actor model characterizes rational behavior as systematic behavior governed by the optimization of expected utility, itself determined by an individual's evaluation of the payoffs and the likelihoods of the payoffs. and the individual's attitude toward risk. (On the rational actor model see Bernoulli. 1738; von Neumann and Norgenstem, 1947; Savage. 1954; Fishbum. 1970: and Jeffrey 1983. On attitude toward risk see Bernoulli, 1738; Pratt. 1964; and Arrow, 1965.) The modem account of the rational actor model has been greatly informed by careful observations of revealed risk attitudes (Fishbum. 1977; Fishbum and Kochenberger. 1979; Battalio. Kagel, and MacDonald, 1985; Battalio, Kugel. and Jiranyakul, 1990.)2

The present analysis employs the modem account of the rationil actor model to provide a refined and extended version of the traditional economic analysis of crime (Becker, 1968, 1995). The discussion presented here is kept consistent with the traditional analysis for two reasons. First, the traditional analysis serves as the foundation for much of the work in the law and economics literature. Second, the results of the tra- ditional analysis provide a justification for the contemporary get-tough-on-crime policies of the federal and various state and local governments in the United States.

The treatment of attiude toward risk is the fundamental refinement of the traditional analysis adopted here. There are three relevant attitudes toward risk: (1) an individual is risk averse if, and only if, the individual's utility function is increasing at a decreasing rate; (2) an individual is risk preferring if, and only if, the individual's utility function is increasing at an increasing rate; and (3) an individual is risk averse/risk preferring if, and only if, the individual is risk averse over gains and risk preferring over losses. Risk aversion is generally viewed as the essence of middle-class normalcy, while risk preference is viewed as an abnormality.

Risk aversion and risk preferring behavior are regularly seen together, and various attempts have been made to explain their joint appearance (Battalio, Kagel. and Jiranyakul, 1990: Battalio, Kagel, and MacDonald, 1985; Camerer, 1989; Fishburn, 1977: Fishbum and Kochenberger, 1979; Friedman and Savage, 1948). Observations of revealed attitude toward risk show that the majority of individuals are risk averse/ risk preferring; that the urility valuation of no change in wealth is zero; and that the utility function is more steeply sloped over losses than over gains (Battalio, Kagel, and Jiranyakul. 1990; Battalio, Kagel, and MacDonald, 1985; Fishbum and Kochenberger, 1979).

The modem work on risk also shows that wealth serves as a parameter in the utility function, and that the utility function can be viewed as a two-dimensional cross-section of a threedimensional surface. For example, a two-piece von Neumann-Morgenstem utility function that exhibits constant absolute risk aversion and constant absolute risk preference is of the general form:

$$
\begin{aligned}
U(\Delta w) & =A\left(1-e^{-B \Delta w}\right) \text { for } \Delta w \geq 0 \\
& =-a\left(1-e^{B \Delta w}\right) \text { for } \Delta w \leq 0
\end{aligned}
$$

where $A$ and $a$ are slope parameters, $B$ is the degree of risk version/risk preference, $\Delta w$ is change in wealth, $a>A>0$, and $B>0$. 
This function is an S-shaped utility function and is displayed in Figure 1.

The related von Neumann-Morgenstern utility surface, as a function of change in wealth, $\Delta w$, and wealth, $w$, is of the general form:

$$
\begin{aligned}
U(\Delta w) & =w^{-1} A\left(1-e^{-B \Delta w}\right) \text { for } \Delta w \geq 0 \\
& =-w^{-1} a\left(1-e^{B \Delta w}\right) \text { for } \Delta w \leq 0
\end{aligned}
$$

This surface is displayed in Figure 2. Note the effect of increasing wealth in Figure 2-the S-shaped utility function, which is a cross-section of the surface, flattens as wealth increases.

\section{THE CRIME DECISION PROBLEM}

The crime decision problem consists of the choice between engaging in a particular criminal act and not engaging in the act. The decision is made on the basis of the individual's perception of the particular crime and the existing criminal justice system at the time of the decision. The decision maker believes that the crime will vield a gain. If caught and punished, the decision maker believes there will be a loss, greater than the gain, imposed by the criminal justice system. The individual assesses the probability, given that the crime is committed, of being punished. The decision not to commit the crime does not carry any gain, but may have some costs imposed by the criminal justice system. For example, an innocent person may be stopped for investigation, detained, arrested, and perhaps even convicted. The cost thus bome is called the harassment cost. The individual assesses the size and the probability of incurring the harassment costs. ${ }^{3}$ In a society with divided legislative, judicial, and executive powers. the value of the fine is primarily set by the decision maker's perception of the law as set dow'n in statutes and by the courts. The values of the harassment cost and the probabilities of being punished and being harassed are primarily set by the decision maker's perception of law' enforcement policies and practices. ${ }^{4}$

Consistent with the rational actor model, the individual chooses between the two acts-com-

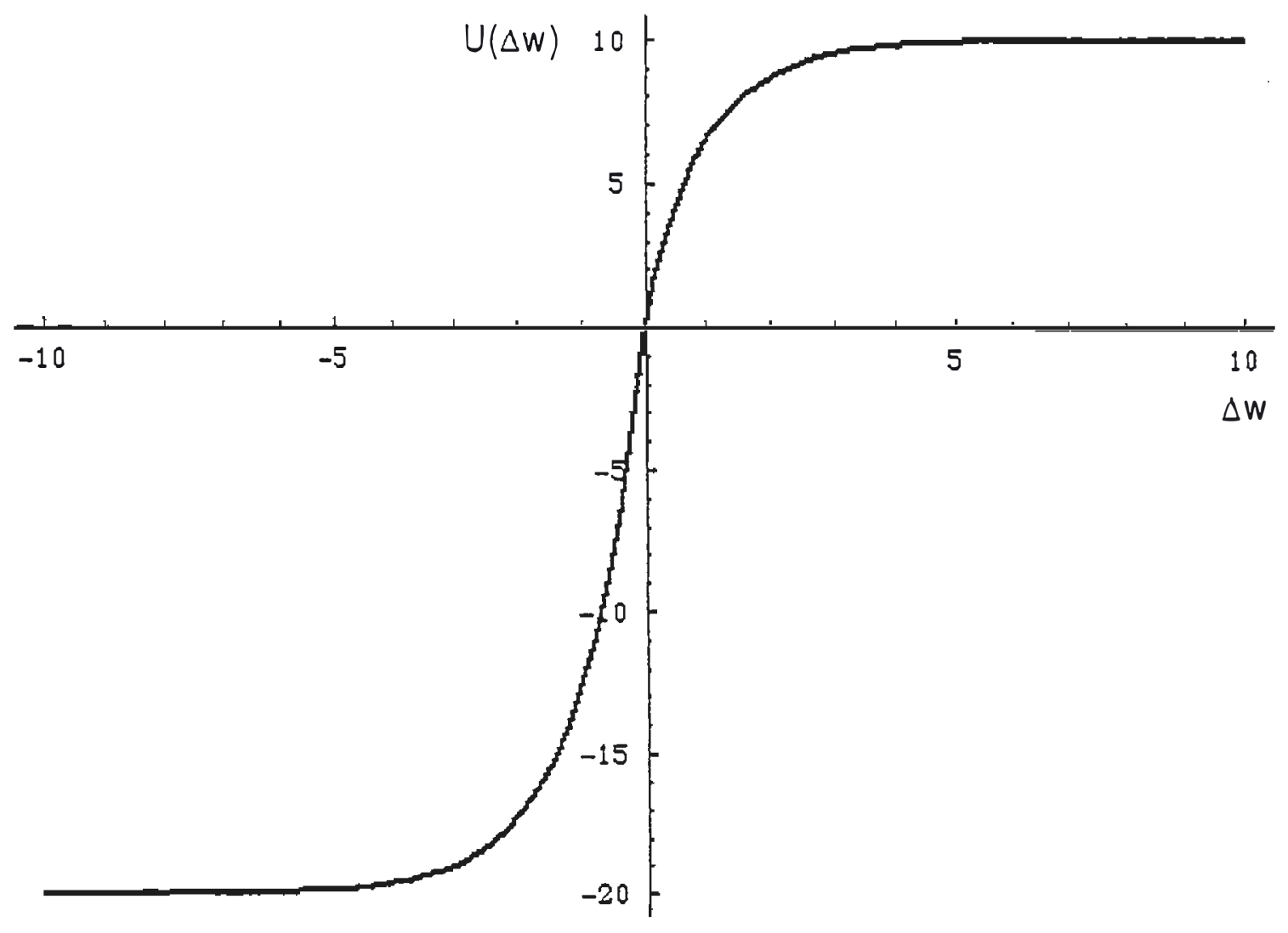

Figure 1. Graph of the Constant Absolute Risk Aversion/Risk Preference von Neumann-Morgenstern Utility Function $(A=10, a=20, B=0.1)$. 


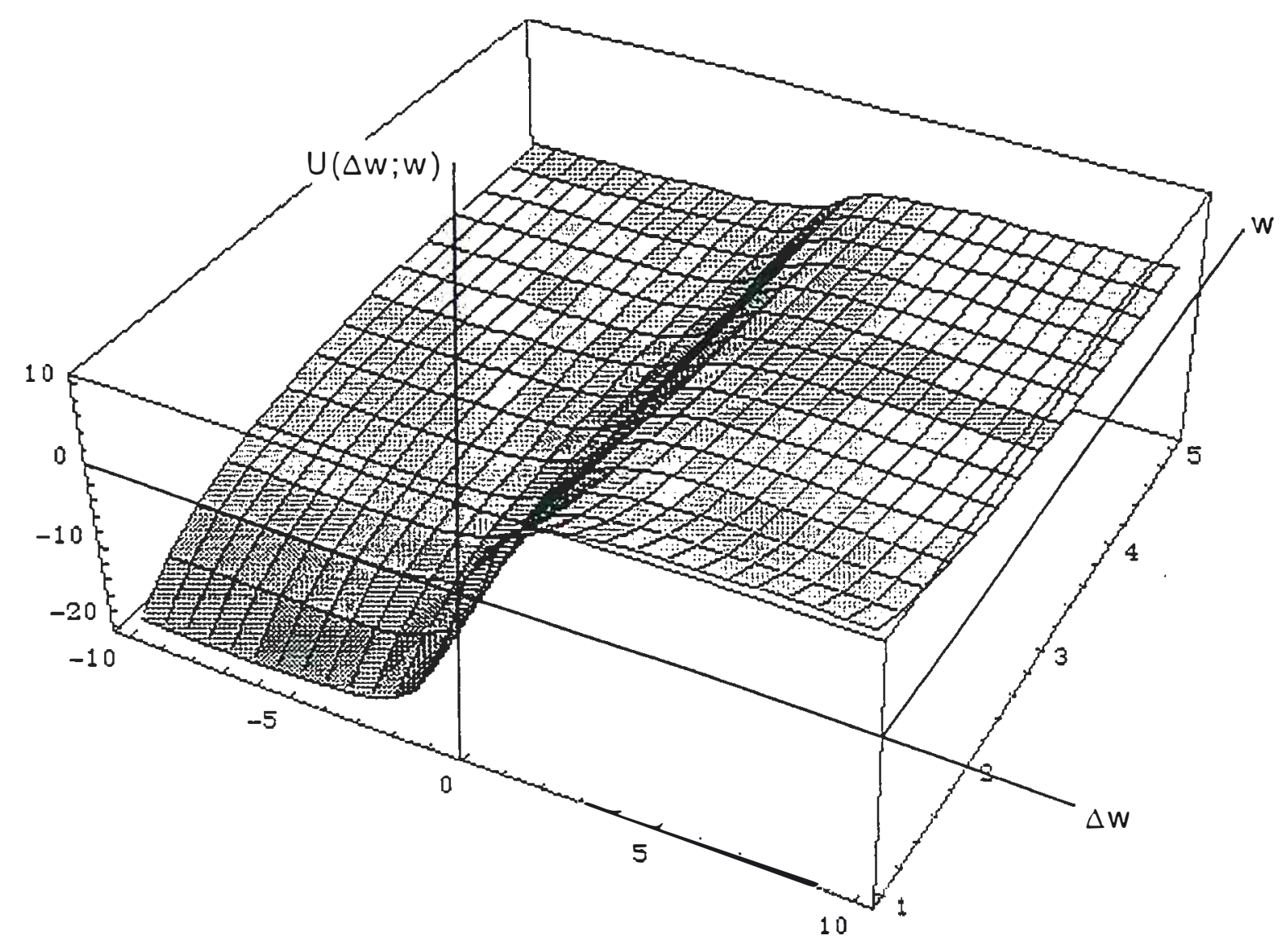

Figure 2. Graph of the Constant Absolute Risk A version/Risk Preference von Neumann-Morgenstem Utility Surface $(A=10, a=20 . B=0.1)$.

mitting and not committing the crime-by applying the utility function to the possible outcomes of the acts, assigning probabilities to the possible states of affairs, and determining the probability weighted utility, called the expected utility, of each act. The act with the greater expected utility is the preferred act. To avoid trivialities, the present analysis is based on the three-part assumption that the gain is positive. the fine is greater than the gain, and the gain less the fine is more negative than the harassment cost. The first two assumptions avoid situations where crime does not pay and where crime always pays: the last is merely the assumption that the criminal justice system is sufficiently accurate to impose. on average, greater costs on criminals who get caught in its web than on noncriminals. The analysis begins with the presumption that the police are more likely to properly intercept the guilty than to improperly intercept the innocent. ${ }^{5}$

The crime decision problem is presented in Table 1 . The parameters are as follows- $g$ is the gain from the crime. $f$ is the fine, $c$ is the harassment cost. $p$ is the probability of rightful punishment, and $q$ is the probability of wrongful

TABle 1

Payoff Thale for the Crime Decision Problem

\begin{tabular}{lcccc}
\hline & $\begin{array}{c}\text { Payoff } \\
\text { If Crime Is } \\
\text { Committed }\end{array}$ & $\begin{array}{c}\text { Probability of } \\
\text { Punishment }\end{array}$ & $\begin{array}{c}\text { Payoff } \\
\text { If Crime Is } \\
\text { Not Committed }\end{array}$ & $\begin{array}{c}\text { Probability of } \\
\text { Harassment }\end{array}$ \\
\hline $\begin{array}{l}\text { Punished or harassed } \\
\text { Not punished or not harassed }\end{array}$ & $g-f$ & $p$ & $-c$ & $q$ \\
\hline
\end{tabular}


harassment. As noted, to avoid trivialities it is assumed that $f>g>0, g-f<-c$, and $p>q \cdot{ }^{6}$ The expected utility of committing the crime is:

$$
E U[\text { crime }]=p U(g-f)+(1-p) U(g),
$$

and the expected utility of not committing the crime is

$$
E U[\text { no crime }]=q U(-c)+(1-q) U(0),
$$

where $E U$ is the individual's expected utility function and $U(0)=0$. The individual prefers committing the crime to not committing the crime if. and only if:

\section{$E U[$ crime $]>E U[$ no crime $]$.}

For an individual deterted from crime, the difference between $E U$ (no crime) and $E U$ (crime) is positive. The difference. denoted by $D$, is:

$$
\begin{aligned}
D & =E U(\text { no crime })-E U(\text { crime }) \\
& =q U(-c)-[p U(g-f)+(1-p) U(g)] .
\end{aligned}
$$

The difference $D$ is a crude measure of deterrence because only two values of $D$ are of interest: $D>0$ and $D<0$. Deterrence is maintained for the individual only. if $D>0$ and is lost if $D<$ 0 . A change in one or more of the parameters. that is. one or more g.f. $c, p$, or $q$, such that $D$ is decreased. reduces deterrence because, as noted. if continued until $D<0$, such a change will make participation in the criminal activity the preferred act.

\section{THE PUNISHMENT-DETERRENCE TRADEOFF}

The analysis presented here addresses one basic question-does a strategy for increasing the punishment of the guilty, $f$, increase deterrence if it has the side effect of increasing the level of harassment. $c$, imposed on those innocently caught up in the criminal justice system? The answer to this question depends upon the individual's attitude toward risk. The answer is positive for risk averse and risk neutral persons. and positive for risk averse/risk preferring persons as long as the probability of punishment, $p$. is reasonably larger than the probability of harassment, q. The answer. however, is negative for risk averse/risk preferring persons if $q$ is close to $p$.

The derivation of this result is straightforward. The response of $D$ to small and equal increases in $f$ and $c$ is given by the total differencial of $D, d D$. where

$$
\begin{aligned}
d D & =\frac{\partial D}{\partial f} d f+\frac{\partial D}{\partial c} d c \\
& =p U^{\prime}(g-f) d f-q U^{\prime}(-c) d c .
\end{aligned}
$$

and

$$
\frac{\partial D}{\partial f} \text { and } \frac{\partial D}{\partial c}
$$

are the partial derivatives of $D$ with respect to $f$ and $c$, respectively. For a risk averse person. $U^{\prime}(g-f)>U^{\prime}(-c)$ because $g-f<-c$ and $U$ is increasing at a decreasing rate. For a risk neutral individual, $U^{\prime}(g-f)=U^{\prime}(-c)$. If $p>q$. then $d D$ is positive for a risk averse or risk neutral person. and the answer to the question is positive. Contrariwise, for a risk preferring or a risk averse/risk prefeming person. $U^{\prime}(g-f)<$ $U^{\prime}(-c)$, because $g-f<-c<0$. and $U$ is increasing at an increasing rate over losses. If $p$ is reasonably larger than $q$, that is. if

$$
\frac{p}{q}>\frac{U^{\prime}(-c)}{U^{\prime}(g-f)},
$$

then $d D$ is positive, and the answer to the question is positive. Contrariwise. if $q$ is close to $p$, that is, if

$$
\frac{p}{q}<\frac{U^{\prime}(-c)}{U^{\prime}(g-f)},
$$

then $d D$ is negative, and the answer to the question is negative.

The foregoing results warrant the following claims. A policy of increasingly severe punishment of both the guilty and the innocent should be a successful deterrent for those individuals, regardless of their attitudes toward risk, who perceive the likelihood of punishment to be reasonably greater than the likelihood of harassment. Such a policy, however, will not be a successful deterrent for individuals who are risk preferring or risk averse/risk preferring if they perceive that the likelihood of harassment is close to or greater than the likelihood of punish- 
ment. Note that the deterrent effect of increasingly severe punishment and harassment depends upon both the decision maker's attitude toward risk and his or her perception of the likelihoods of punishment and harassment. Finally, note that the foregoing analysis concerns only the individual's movement toward committing the crime. The individual chooses to commit the crime if and only if $D<0$, that is, if and only if.

$$
\frac{p}{q}<\frac{\frac{1}{q} U(g)-U(-c)}{U(g)-U(g-f)} .
$$

Because

$$
\frac{1}{q} U(g)>U(g)
$$

and

$$
U(g-f)<U(-c),
$$

the right-hand side of this inequality does not have a unique relarionship to unity. Therefore. $q$ need not exceed $p$ in order for committing the crime to be the preferred act.

\section{RISK ATTITLDE. HARASSIVIENT, AND U.S. PRISON DEMOGRAPHICS}

The policy implications of the foregoing analysis are straightiorward. Any policy that increases the severity of both the punishment of the guilty and the harassment of the innocent. such as a war on crime. may tend to induce criminal behavior among those who are risk averse/risk preferring and perceive similar likelinoods of being rightfully punished or wrongfully harassed. The traditional economic analysis of crime explains criminal activity by positing that most criminals are inveterate risk takes, that is. habirually risk preferring over both loses and gains. This explanation, although consistent with the analysis presented here, has two glaring weaknesses. First, risk preference over gains is rare (Fishburn and Kochenberger. 1979) and criminal activity is not. Second. because a disproportionate number of criminals in the U.S. prison system come from minority groups. the traditional explanation requires the presumption that dispropor- tionately many members of minorities are risk preferring over gains. (See, generally, Horney and Marshall, 1992; Katz, 1991; Keane, Gilli, and Hagan, 1989; Rand, 1992; Sherman, 1990; Li.S. Department of Justice, 1991; Williams and Hawkins, 1986; Yu and Liska, 1993; Zimring and Hawkins, 1973.)

The analysis advanced here presents the theoretical basis for a possibly superior (partial) explanation of the demographics of the American prison population. The explanation proffered here makes two simple presumptions. First, it is presumed that minority populations have the same distribution of attitudes toward risk as the general population. Second, it is presumed that many minority individuals see themselves as regular recipients of harassment, and thereby perceive the probability of harassment as close to, or even greater than. the probability of rightful punishment. ${ }^{9}$ This perception, and not some odd concentration of a rare attitude toward risk. explains some. but not all, of the disproportionate number of African American, Native American, and Latino prisoners in the U.S. penal system.

Vote that a claim is not made here that the foregoing argument explains the whole of U.S. prison demographics. The literarure on the causes of crime offers many potential causes, including poverty, opportunity. and risk preference. Members of minorities are disproportionately well represented among the poor, and they may have greater opportunities for crime. It is not likely, however, that they disproportionately possess a rare attitude toward risk. The foregoing argument, based only on the presumption that minority individuals perceive a probability of harassment that is close to the probability of punishment, thus provides a superior explanation of some of the disproportionate minority representation in the U.S. prison system.

\section{ASPECTS OF FAIRNESS IN CRIMINAL JUISTICE}

In an ideal society both $q$ and $c$ would be very close to zero. In such a society, a law abiding citizen would have a very low likelihood of contact with the police or the legal system, and 
any contact that did occur would be at most a minor inconvenience. This property of an ideal society is one of the many facets of the notion of faimess.

Most accounts of societal faimess are related to wealth or income distribution. Bueno de Mesquita and Cohen (1995) provides a gametheoretic model of criminal choice in which faimess is introduced as wealth redistribution. Specifically, the goremment is fair (or trustworthy) if it imposes "policies that promote opportunities for the citizens." and it is unfair (or untrustworthy) if it imposes "policies that shift resources to the government to be used as the govermment sees fit" (Bueno de Mesquita and Cohen, 1995:494). Similariy. Young (1994) provides an extensive formal treatment of faimess as equity. On this riew. a society is fair if "the division of jointly produced goods [is made in a way that the] sociert considers to be appropriate to the need, status. and contribution of its various members" (Young. 1994:3).

The notion of faimess employed in the present article has a mucin more limited scope and focuses on the implementation of the procedures. rules, and laws of the legal system. In this view, the legal system is fair to an individual facing the crime decision problem only if the probability of punishment, $p$, is reasonabiy larger than the probability of harassment, $q$ : and the harassment cosi. $c$. is close to zero. The legal system is unfair if $q$ is close to $p$, or $c$ is reasonably larger than zero. or both.

The results derived above can be restated in terms of the (limited) notion of faimess. If the legal system is unfair in the strong form of the sense employed here (i.e.. if $q$ is close to $p$ and $c$ is greater than zerol. then the individual moves toward and ultimately chooses the criminal act. Given the general perception that the legal system is unfair, in the sense used here, particularly to African Americans, Native Americans, and Latinos, it is not surprising that members of these minorities are disproportionately well represented in the American penal system.

The notion of faimess as equitable wealth distribution can be accounted for here by considering different wealth levels of the decision maker. The effect of wealth on the S-shaped utility function was detailed above-the utility surface flattens as wealth increases. Thus, those individuals who are treated unfairly with respect to wealth distribution will have more eccentric utility functions than those who are treated fairly. A formal analysis of this effect is beyond the scope of the present article. Note, however. that because an S-shaped utility function is more steeply sloped on the loss side, the effect of greater eccentricity is to give greater weight to the risk preferring segment of the utility function. Thus, in general, unfaimess with respect to wealth will lead to greater levels of criminal activity in the present model. In particular, it is easy to show that for an individual facing given values of the parameters $g, f, c, p$, and $q$, it is not possible to have crime preferred to no crime at a high wealth level and no crime preferred to crime at a low wealth level.

\section{ACKNOWLEDGMEITS}

The authors thank Matti Joutsen. Eric Jensen. Mark Anderson. and three anonymous referees for their comments and suggestions.

\section{NOTES}

1. On the economic analysis of the crime decision see. particularly. Becker (1968. 1995i and. generally, Ehrlich and Becker (1972), Ehrlich (19i3). Block and Heineke (1975). and Posner (1980). On the game-theoretic analysis see Bueno de Mesquita and Cohen (1995). The traditional economic analysis, particularly Becker (1968), considers altemative risk attitudes. but does not consider either the risk averseirisk preferring attitude or harassment. The Bueno de Mesquita-Cohen (1995) analysis assumes that the decision maker is risk neutral. and also does not consider harassment. The former point is clear from the calculation of the expected utility for a criminal (Bueno de Mesquita and Cohen. 1995:497). This calculation is linear in payoffs and thereby presumes a linear (i.e.. risk neutral) utility function. The latter point is made by Bueno de Mesquita and Cohen as follows: "To keep our analysis as simple as possible at this stage in our research, we assume that no one is mistakenly arrested and convicted. and we assume that everyone who is apprehended is guilty and conricted" (Bueno de Mesquita and Cohen, 1995:497. footnote 8).

2. Parallel work is presented in Kahneman and Tversky (1979) and Tversky and Kahneman (1992). Please note that these studies present and refine Prospect Theory, which is not consistent with the expected utility theory employed in Becker (1968, 1995), Bueno de Mesquita and Cohen (1995). and in the present article.

3. See Horney and Marshall (1992) for evidence that among criminals these perceptions are formed in a manner consistent with the rational actor model. See Yu and Liska 
(1993) on the perception of the likelihood of punishment in a study disaggregated by race.

4. The present analysis takes a middle path in defining the costs of involvement with the criminal justice system. and falls between the official criminal sanction (the sentence only) and all conceivable costs (such as humiliation in the community). The latter are described as informal sanctions in an expanded concept of deterrence in Nagin and Paternoster (1991). Property forfeiture by the innocent. which has become increasingly common in the United States. is treated by Jensen and Gerber (1996).

5. There is one interesting case where the two probabilities are approximately equal-when law enforcement-citizen interactions involve random selection of persons for investigation. This would be the case where drunk driving is detected primarily through randomly established roadblocks or tax evasion is discovered primarily by randomly auditing citizens' tax renums. There are a number of cases where the probability of wrongful harassment is close to or greater than the probability of punishment for members of certain groups-when profiles, based on physical or physiological traits related to race and ethnicity, are employed by law enforcement officials to make stops and to detain individuals.

6. Although each of $g, f$, and $c$ is here viewed as a single value, each is more accurately viewed as the moment of a probability distribution. For example, a prospective criminal does not know the exact value to be gained from a crime, such as the exact amount of money that can be stolen from a bank. As a moment, the gain $g$ is the expected value of a random variable with possible values $g_{1}, g_{2} \ldots, g_{n}$ each with probabilities $P\left(g_{1}\right), P\left(g_{2}\right), \ldots, P\left(g_{n}\right)$. Then $g=$ $\sum_{i} g_{i} P\left(g_{i}\right)=g_{1} P\left(g_{1}\right)+g_{2} P\left(g_{2}\right)+\ldots+g_{n} P\left(g_{n}\right)$.

Similarly. $f$ and $c$ are moments with $f=\sum_{-i} f_{i}\left(f_{i}\right)$ and $c=$ $\Sigma_{\mathrm{i}} c_{\mathrm{i}} P\left(c_{\mathrm{i}}\right)$. The treatment of $g, f$, and $c$ as moments does not markedly detract from the generality of the analysis because $g, f$, and $c$ can be considered as independent random variables, and. therefore, the lotteries (i.e., the full expansion of the terms) can be replaced with the moments (Luce and Raiffa, 1967:23-31).

The payoff table for the general case where $g, f$, and $c$ can take on various values is shown in Table 2 . In Table 2 ,

$\Sigma_{\mathrm{i}} P\left(g_{\mathrm{i}}\right)+\Sigma_{\mathrm{i}} \Sigma_{\mathrm{j}} P\left(g_{\mathrm{i}}-f_{\mathrm{j}}\right)=1$ and $P(0)+\Sigma_{\mathrm{i}} P\left(-c_{\mathrm{i}}\right)=1$.

The expected utilities are then

$$
E U(\text { crime })=\Sigma_{\mathrm{i}} P\left(g_{\mathrm{i}}\right) U\left(g_{\mathrm{i}}\right)+\Sigma_{\mathrm{i}} \Sigma_{\mathrm{j}} P\left(g_{\mathrm{i}}-f_{\mathrm{j}}\right) U\left(g_{\mathrm{i}}-f_{\mathrm{j}}\right)
$$

and

$$
E U(\text { no crime })=P(0) U(0)-\Sigma_{\mathrm{i}} P\left(-c_{\mathrm{i}}\right) U\left(-c_{\mathrm{i}}\right) .
$$

7. An interesting limiting case. raised by a reviewer. arises when the harassment payoff. $-c$, approaches the loss from crime, $g-f$. Considering just the payoffs, if $g-f=$ $-c$, then committing the crime dominates not committing the crime. This is so because the payoffs to both acts are equal given that the individual is punished and the payoff to the former is greater than that to the latter. given that the individual is not punished. The probabilities, $p$ and $q$, however, are not equal, and. therefore. simple dominance in payoffs does not resolve the problem. If $g-f=-c$, then the deterrence measure. $D$. becomes

$$
D=[q U(-c)+(1-q) U(0)]-[p U(-c)+(1-p) U(g)]
$$

so that

$$
D=(q-p) U(-c)-(1-p) C^{\prime}(g) .
$$

Because $U(-c)<0$ and $U(g)>0$. if $p$ is close to unity. so that $(1-p) U(g)$ is close to zero. then $D$ is positive and deterrence is maintained. If. however. $q$ is close to $p$. so that $(q-p) U(-c)$ is close to zero. then $D$ is negative and deterrence is lost. Thus, if $g-f=-c$, then deterrence is main-

\begin{tabular}{|c|c|c|c|c|}
\hline & $\begin{array}{c}\text { Payoff } \\
\text { If Crime is } \\
\text { Committed }\end{array}$ & $\begin{array}{l}\text { Probability of } \\
\text { Punishment }\end{array}$ & $\begin{array}{c}\text { Payoff } \\
\text { If Crime is } \\
\text { Not Committed }\end{array}$ & $\begin{array}{c}\text { Probability of } \\
\text { Harassment }\end{array}$ \\
\hline 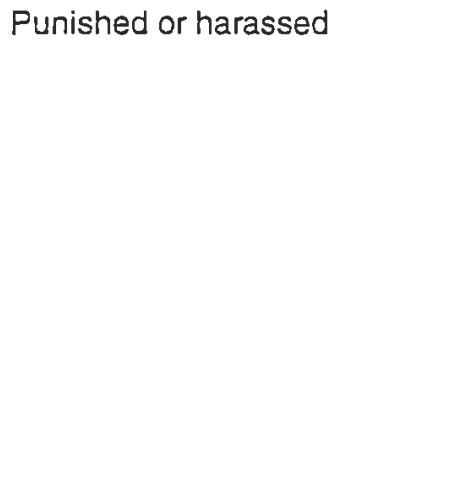 & $\begin{array}{c}g_{1}-f_{1} \\
g_{1}-f_{2} \\
\vdots \\
g_{1}-f_{n} \\
g_{2}-f_{1} \\
g_{2}-f_{2} \\
\vdots \\
g_{2}-f_{n} \\
\vdots \\
g_{m}-f_{1} \\
g_{m}-f_{2} \\
\vdots \\
g_{m}-f_{n}\end{array}$ & $\begin{array}{c}P\left(g_{1}-f_{1}\right) \\
P\left(g_{1}-f_{2}\right) \\
\vdots \\
P\left(g_{1}-f_{n}\right) \\
P\left(g_{2}-f_{1}\right) \\
P\left(g_{2}-f_{2}\right) \\
\vdots \\
P\left(g_{2}-f_{n}\right) \\
\vdots \\
P\left(g_{m}-f_{1}\right) \\
P\left(g_{m}-f_{2}\right) \\
\vdots \\
P\left(g_{m}-f_{n}\right)\end{array}$ & $\begin{array}{c}-c \\
-c \\
\vdots \\
-c\end{array}$ & $\begin{array}{c}P\left(-c_{1}\right) \\
P\left(-c_{2}\right) \\
\vdots \\
P\left(-c_{1}\right)\end{array}$ \\
\hline Not punished or not harassed & $\begin{array}{c}g_{1} \\
g_{2} \\
\vdots \\
g_{k}\end{array}$ & $\begin{array}{c}P\left(g_{1}\right) \\
P\left(g_{2}\right) \\
\vdots \\
P\left(g_{k}\right)\end{array}$ & 0 & $P(0)$ \\
\hline
\end{tabular}
tained only if $p$ is large absoluteiy and relative to $q$.

TABLE 2

Payoff Table for the General Case of the Crime Decision Pacelem 


\section{Becker writes as follows:}

It is easily shown that an increase in $p_{\mathrm{j}}$ would reduce the expected utility [of committing the crime], and thus the number of offenses, more than an equal percentage increase in $f_{\mathrm{j}}$ if [individual $j$ ] has a preference for risk; the increase in $f_{\mathrm{j}}$ would have the greater effect if he has aversion to risk: and they' would have the same effect if he is risk neutral. The widespread generalization that offenders are more deterred by the probability of conviction than by the punishment when convicted turns out to imply in the expected-utility' approach that offenders are risk preferrers. at least in the relevant region of punishments. (Becker, 1968:178)

Becker recently' reiterated this vieu:

I believe that criminals actually like risk-they're risk takers. not avoiders. What supports this belief? The economic approach implies that. for a risk taker engaged in crime. the certainty of punishment is more important than the magnitude of the punishment when or if you are convicted. (Becker, 1995:11)

The comparison of equal percentage changes in $p$ and $f$ in the model employed here produces somewhat more sophisticated results. It is easy to shou that an increase in $p$ reJuces the expected utility of crime by more than an equal percentage change in $f$ only if the value of $f$ is already reasonably high. More specifically: for an individual with the $S$-shaped utility function facing the crime decision problem with $c=0$. an increase in $p$ has a greater deterrent effect than an equal percentage change in $f$ only if $f>f_{1}$ where $f_{1}$ is determined by the equation

$$
L^{\prime \prime}\left(g-f_{1}\right)=\frac{U(g)-U^{\prime}\left(g-f_{1}\right)}{f_{1}}
$$

I Geometrically. this equation states that $f_{\mathrm{t}}$ is determined so that the chord from the point $[g . U(g)]$ to the point $[g-$ $\left.\therefore . C\left(g-f_{1}\right)\right]$ is tangent to the utility function at $\left[g-f_{t} U(g-\right.$ $r_{1}(1)$. I The widespread generalization that increasing $p$ has a greater deterrent effect than increasing $f$ implies in the expected utility approach, extended and refined via the S-shaped utility function. that most potential offenders face crime decision problems where the level of punishment is already high (i.e., probiems where $f>f_{1}$ ).

9. Yu and Liska (1993) provide a sample (from 26 U.S. cities) that suggests that this perception by African Americans is, for assaults and rapes. well supported. They note that "blacks contribute $76 \%$ of the robbery arrests and $76 \%$ of the robberies; $65 \%$ of the assault arrests and $50 \%$ of the assaults; and $73 \%$ of the rape arrests and $55 \%$ of the rapes" (Yu and Liska, 1993:455-6. footnote 9). Hagedom and Macon (1988) and Jankowski (1991) report anecdotal evidence that minority individuals in gangs perceive themselves to be harassed by the police.

\section{REFERENCES}

Arrow, K. J. (1965). The theory of risk aversion. In Aspects of the theory of risk-bearing. ed. K. J. Arrow. Helsinki: Yrjö Jahnsson Foundation.

Battalio, R., Kagel, J., and Jiranyakul, K. (1990). Testing between alternative models of choice under uncertainty:
Some initial results. Joumal of Risk and Uncerrainn. 3:25-50.

Battalio. R.. Kagel. J., and MacDonald, C. (1985). Animals' choices over uncertain outcomes: Some initial experimental results. American Economic Review 75:597-613.

Becker. G. (1968). Crime and punishment: An economic approach. Joumial of Political Economy 78:169-217.

Becker. G. (1995). The economics of crime. Federal Reserie of Richmond 12:9-15.

Bernoulli. D. (1738). Specimen theoriae novae de mensura sortis. Commentarii Academiae Scientiarum Imperialis Perropolitanae 5:175-92. Translated by L. Sommer (1954).

Block. M.. and Heineke, J. (1975). A labor theoretic analysis of the criminal choice. American Economic Review. 65:314-25.

Camerer. C. (1989). An experimental test of several generalized utility theories. Journal of Risk and Uncertainn. 2:61-104.

Ehrlich. I. (1973). Participation in illegitimate activities: A theoretical and empirical investigation. Joumal of Political Economy 81:521-65.

Ehrlich. I., and Becker, G. (1972). Market insurance. selfinsurance. and self-protection. Joumnal of Political Economy 80:623-t8.

Fishbum. P. (1970). Utility theorn and decision making. New: York: John Wiley \& Sons.

Fishburn. P. (1977). Mean-risk analysis with risk associated with below-target retums. American Economic Review 67:116-26.

Fishburn. P.. and Kochenberger, G. (1979). Two-piece von Neumann-Morgenstern utility functions. Decision Sciences 10:503-18.

Friedman. M.. and Savage. L. J. (1948). The utility analysis of choices inrolving risk. Joumal of Political Economy. 56:279-304.

Hagedom, J.. and Macon. P. (1988). People and folks: Gangs. crime and the underclass in a rust belt ciñ. Chicago: Lake View Press.

Homey. J., and Marshall, I. (1992). Risk perceptions among serious offenders: The role of crime and punishment. Criminolog. 30:575-92.

Jankowski. M. (1991). Islands in the street. Berkeley. CA: University of California Press.

Jensen. E. L.. and Gerber, J. (1996). The civil forfeiture of assets and the war on drugs: Expanding criminal sanctions while reducing due process. Crime and Delinquency. 42:421-34.

Jeffrey. R. C. (1983). Logic of decision. Chicago: University of Chicago Press.

Kahneman. D.. and Tversky. A. (1979). Prospect theory: An analysis of decisions under risk. Econometrica 47:263-91.

Katz. J. (1991). The motivation of the persistent robber. In Crime and justice: A revien of research. ed. M. Tonry. Chicago: Liniversity of Chicago Press.

Keane. C.. Gillis. R.. and Hagan. J. (1989). Deterrence and amplification of juvenile delinquency by police contact. British Jounzal of Criminology 29:336-5?.

Luce. R. D.. and Raiffa, H. (1967). Gumes and decisions. New York: John Wiley \& Sons.

Nagin. D., and Patemoster, D. (1991). The preventive effects of the perceived risk of arrest: Testing an expanded conception of deterrence. Criminology 29:561-87.

Posner, R. (1980). Retribution and related concepts of punishment. Joumial of Legal Studies 9:71-92.

Pratt. J. (196t). Risk aversion in the small and the large. Econometrica 32:122-36. 
Rand. (1992). Rand analysis charts L.A. riot arrest and crime parterns-arrestees show distinctive demographic profile; Latinos predominate. Santa Monica. CA: Rand.

Savage, L. J. (1954). Foundations of statistics. New York: John Wiley \& Sons.

Sherman, L. (1990). Police crackdowns: Initial and residual deterrence. In Crime and justice: A review of research, eds. M. Tonry and N. Morris. Chicago: University of Chicago Press.

Tversky, A., and Kahreman, D. (1992). Advances in prospect theory: Cumulative representation of uncertainty. Journal of Risk and Uncertainty 5:297-323.

U.S. Department of Justice, Federal Bureau of Investigation. (1991). Uniform crime reports 1990: Crime in the
United States. Washington, DC: U.S. Government Printing Office.

von Neumann, J., and Morgenstem, O. (1947). Theory of games and economic behavior. $2 \mathrm{~d}$ ed. Princeton, NJ: Princeton University Press.

Williams, K., and Hawkins, R. (1986). Perceptual research on general deterrence: A critical review. Law and Society Review 20:545-72.

Yu, J., and Liska, A. E. (1993). The certainty of punishment: A reference group effect and its functional form. Criminology 31:447-64.

Zimring, F., and Hawkins, G. (1973). Deterrence. Chicago: University of Chicago Press. 